\title{
Research on Logistics Delivery Model Based on Optimization Algorithm
}

\author{
YUAN Xu-hua \\ College of Mathematics and Computer Science,Yan’an University,Yanan 716000,China
}

\author{
Keywords: Logistics Distribution, Path, Optimization, Mathematical Model
}

\begin{abstract}
In order to save the cost of logistics distribution company, the route optimization of logistics distribution vehicle scheduling and the time optimization problem in distribution processing are studied. The workflow of logistics distribution company is mainly divided into four parts: order transportation, warehousing processing, distribution processing and distribution transportation. First of all, the background and current situation of logistics distribution are briefly introduced. Then, the basic algorithm of route optimization in distribution transportation process is summarized. The model of vehicle delivery route optimization based on time window constraint is given. At the same time, the model is verified by saving algorithm, sweeping algorithm and neighbor algorithm. Finally, the advantages and disadvantages of various schemes are compared. The three methods proposed in this paper can save costs in varying degrees. By comparing the three methods, the results show that the saving algorithm is superior.
\end{abstract}

\section{Introduction}

The development of China's distribution industry is relatively slow compared with foreign countries. The distribution mode is also changing and updating with the development of production. It has gone through the following three stages [1]. The first stage is the embryonic stage of distribution development. In the early 1960s, logistics was a simple delivery. People have begun to develop the general delivery to prepare the processing of goods. The second stage is the growth stage of distribution development. In the mid-1960s, as the economy started to develop, the demand for commodities began to increase and the circulation of goods became more and more frequent. As a result, the distribution industry began to develop. The third stage is the mature stage of distribution development. From the late 80s of the last century to now, the distribution industry has developed to a certain scale. The distribution center came into being. People put forward higher requirements on the quality of delivery. Logistics and distribution vehicle optimization scheduling problem called vehicle routing problem (VRP) [2]. The problem is defined as: for some established customers, the right vehicle routing is selected. According to the constraints of specific problems, the purpose is to achieve certain goals (such as the shortest path, the least total cost, etc.). At present, the path optimization algorithm has optimization method, the traditional heuristic algorithm and modern heuristic algorithm [3]. The optimization method includes dynamic programming, branch and bound method and tangent plane method. The traditional heuristic algorithms include saving algorithm, insertion algorithm, neighbour algorithm and sweeping algorithm. The modern heuristic algorithms include genetic algorithm, taboo search algorithm, simulated annealing algorithm and ant colony algorithm [4].

\section{Vehicle scheduling model based on time window constraint}

VRP (Vehicle Routing Problem) is the most basic model to solve the problem of large-scale logistics companies or distribution entities. Based on this, the constraint on the time of joining a customer is the VRPTW model, and many problems are considered on this basis. This problem has long been proved to be a NP-Hard problem, and there is no good solution [5]. The schematic diagram of the VRP problem is shown in Figure 1. 


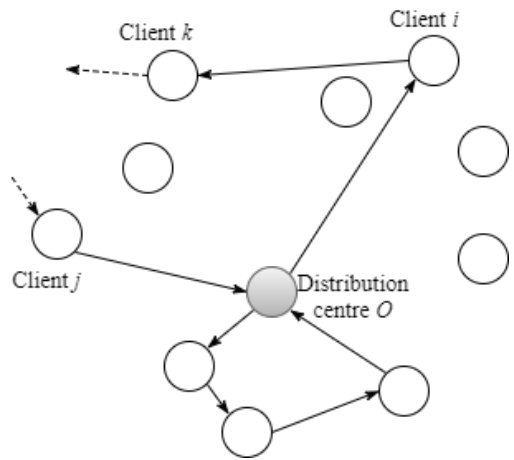

Figure 1. The schematic diagram of the VRP problem

Assumptions: Only one distribution enterprise, all vehicles start from here; The length of the distance between the distribution enterprise and the customer points is known; The amount of demand per customer is known; The needs of each client are met; A car has only one route, and starting from the distribution business, back to the distribution business; A car can deliver for multiple customers; The maximum capacity of each car is known; The total amount of each shipment of the vehicle cannot exceed the maximum capacity of the vehicle; Each customer can only accept one delivery, and within its allowable time range; The time range acceptable to each customer is known.

In the above model, the number of optional distribution path schemes will increase exponentially with the number of customers increasing. For a single loop problem with 20 nodes, it takes more than 300 years to compute the total number of paths that can be computed even one billion times per second [6-7]. The routing problem of logistics distribution is a multi-loop problem, and the calculation will be more complex. Therefore, the optimal routing problem of logistics distribution is a NP hard problem, and it is difficult to obtain the exact solution. For practical problems, when the number of customers is small, and the transportation network is simple, some need only to obtain satisfactory solutions or relatively good solutions. Some specific constraints can be added at this point. The exhaustive method can be used to obtain the exact optimal solution of the vehicle routing problem with logistics distribution. For example, in practical problems, a logistics company's business volume is not very large. According to the different customer needs, many customers will be divided into customer groups. In this way, heuristic algorithm can be used completely. Moreover, heuristic algorithms have significant advantages in solving small scale problems [8].

\section{Experiment}

\subsection{Case analysis}

A logistics company needs to deliver goods to 9 customers. Under the condition that the time constraint of each customer point is considered, the vehicle arrangement scheme is calculated, and the total transportation cost is minimum. There is a 6-ton car (100 km fuel consumption 20L), two 10 -ton vehicles (100 km fuel consumption 26L), diesel 05.7 yuan per liter, give drivers a daily wage of 150 yuan. The maximum capacity of 6 -ton vehicle is 60 boxes of goods, and the maximum load of 10-ton vehicle is 100 boxes of goods. The demand and delivery distance of each customer is shown in Table 1.

Table 1. The demand and delivery distance of each customer

\begin{tabular}{|l|l|l|l|l|l|l|l|l|l|}
\hline Customer & A1 & A2 & A3 & A4 & A5 & A6 & A7 & A8 & A9 \\
\hline $\begin{array}{l}\text { Freight } \\
\text { volume } \\
\text { (box } \\
\text { week) }\end{array}$ & 36 & 24 & 24 & 12 & 16 & 44 & 14 & 18 & 40 \\
\hline $\begin{array}{l}\text { Distance } \\
(\mathrm{km})\end{array}$ & 76.1 & 88.9 & 187.0 & 172.1 & 59.2 & 155.3 & 86.9 & 82.3 & 84 \\
\hline
\end{tabular}

Then, considering the time constraints, according to the actual needs of each customer, the time constraint table is worked out, as shown in Table 2 . The departure time is $t_{0}=0 . e_{i}$ represents the 
time when the customer $\mathrm{i}$ begins to receive the goods. $l_{i}$ represents the time when the customer $\mathrm{i}$ receives the goods at the latest.

Table 2. Time constraints for each customer point

\begin{tabular}{|l|l|l|l|l|l|l|l|l|l|}
\hline Customer & A1 & A2 & A3 & A4 & A5 & A6 & A7 & A8 & A9 \\
\hline$\left(\mathrm{e}_{\mathrm{i}}, \mathrm{l}_{\mathrm{i}}\right)$ & $(1,3)$ & $(2,4)$ & $(3,5)$ & $(4,6)$ & $(1,5)$ & $(3,6)$ & $(4,8)$ & $(1,6)$ & $(1,8)$ \\
\hline
\end{tabular}

\subsection{The original distribution programs}

As the demand is not more than 60 boxes, they can choose 6 tons of cars for transport. The logistics company aims at the small demand customers. The basic situation of distribution is shown in Table 3. The distribution route is shown in Figure 2.

Table 3. The basic situation of distribution

\begin{tabular}{|l|l|l|l|l|}
\hline Loop & Distance & $\begin{array}{l}\text { The volume of } \\
\text { goods }\end{array}$ & Car model & $\begin{array}{l}\text { Number } \\
\text { drivers }\end{array}$ \\
\hline $0-1-2-0$ & $214.2 \mathrm{~km}$ & 60 & 6 tons of cars & 1 \\
\hline $0-3-4-0$ & $376.3 \mathrm{~km}$ & 36 & 6 tons of cars & 2 \\
\hline $0-5-6-0$ & $320.2 \mathrm{~km}$ & 60 & 6 tons of cars & 1 \\
\hline $0-7-8-0$ & $205.1 \mathrm{~km}$ & 32 & 6 tons of cars & 1 \\
\hline $0-9-0$ & $168.0 \mathrm{~km}$ & 40 & 6 tons of cars & 1 \\
\hline
\end{tabular}

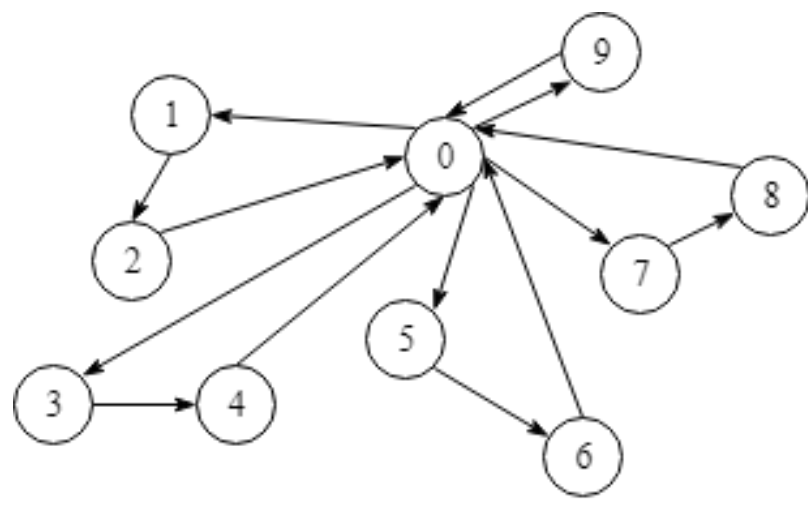

Figure 2. The distribution routes

The above schemes are easy to verify and conform to the time constraints, that is, within the time constraint, the goods can be delivered to each customer on time. The calculation result of the original scheme is shown in Table 4.

Table 4. The calculation result of the original scheme

\begin{tabular}{|l|l|l|l|l|}
\hline Item & Total mileage & $\begin{array}{l}\text { Fuel } \\
\text { consumption }\end{array}$ & $\begin{array}{l}\text { Number of } \\
\text { drivers }\end{array}$ & Total cost \\
\hline Original scheme & 1283.9 & 256.76 & 6 & 2710.16 \\
\hline
\end{tabular}

\subsection{Distribution scheme based on saving algorithm}

The saving algorithm is a method to optimize the route of transportation vehicle, that is, to reduce the distance of vehicle transportation as much as possible, so as to improve the efficiency of vehicle transportation. The optimization scheme of saving algorithm is shown in Table 5. The calculation results of the saving algorithm are shown in Table 6. The distribution route of saving algorithm is shown in Figure 3.

Table 5. The optimization scheme of saving algorithm

\begin{tabular}{|l|l|l|l|l|}
\hline Loop & Distance & $\begin{array}{l}\text { The volume of } \\
\text { goods }\end{array}$ & $\begin{array}{l}\text { Car model } \\
\text { drivers }\end{array}$ \\
\hline $0-3-4-6-7-0$ & $455.9 \mathrm{~km}$ & 94 & 10 tons of cars & 2 \\
\hline $0-1-2-5-0$ & $233.7 \mathrm{~km}$ & 76 & 10 tons of cars & 1 \\
\hline $0-8-9-0$ & $257.1 \mathrm{~km}$ & 58 & 6 tons of cars & 1 \\
\hline
\end{tabular}


Table 6. The computational results of the saving algorithm

\begin{tabular}{|l|l|l|l|l|}
\hline Item & Total mileage & $\begin{array}{l}\text { Fuel } \\
\text { consumption }\end{array}$ & $\begin{array}{l}\text { Number of } \\
\text { drivers }\end{array}$ & Total cost \\
\hline $\begin{array}{l}\text { Saving } \\
\text { algorithm }\end{array}$ & 946.7 & 230.7 & 4 & 2226.4 \\
\hline
\end{tabular}

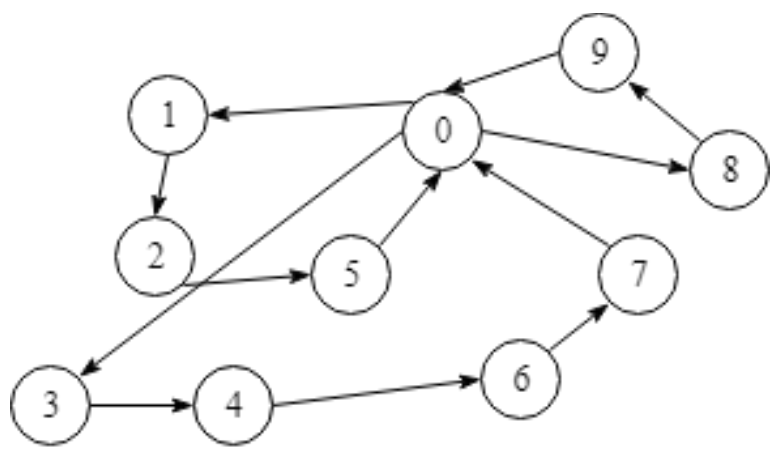

Figure 3. The distribution route of saving algorithm

\subsection{Distribution scheme based on sweeping algorithm}

According to the vehicle carrying capacity, the customer group is scanned. They are numbered and grouped according to the order of scan. Then, an algorithm for selecting the optimal path within a group is presented. The optimization scheme of the sweeping algorithm is shown in Table 7. The calculation results of the sweeping algorithm are shown in Table 8. The distribution route of the sweeping algorithm is shown in Figure 4.

Table 7. The optimization scheme of the sweeping algorithm

\begin{tabular}{|l|l|l|l|l|}
\hline Loop & Distance & $\begin{array}{l}\text { The volume of } \\
\text { goods }\end{array}$ & Car model & $\begin{array}{l}\text { Number } \\
\text { drivers }\end{array}$ \\
\hline $0-1-2-3-4-0$ & $412.7 \mathrm{~km}$ & 96 & 10 tons of cars & 2 \\
\hline $0-5-6-7-8-0$ & $367 \mathrm{~km}$ & 92 & 10 tons of cars & 2 \\
\hline $0-9-0$ & $168.0 \mathrm{~km}$ & 40 & 6 tons of cars & 1 \\
\hline
\end{tabular}

Table 8. The calculation results of the sweeping algorithm

\begin{tabular}{|l|l|l|l|l|}
\hline Item & Total mileage & $\begin{array}{l}\text { Fuel } \\
\text { consumption }\end{array}$ & $\begin{array}{l}\text { Number of } \\
\text { drivers }\end{array}$ & Total cost \\
\hline $\begin{array}{l}\text { Sweeping } \\
\text { algorithm }\end{array}$ & 947.7 & 236.3 & 5 & 2415.9 \\
\hline
\end{tabular}

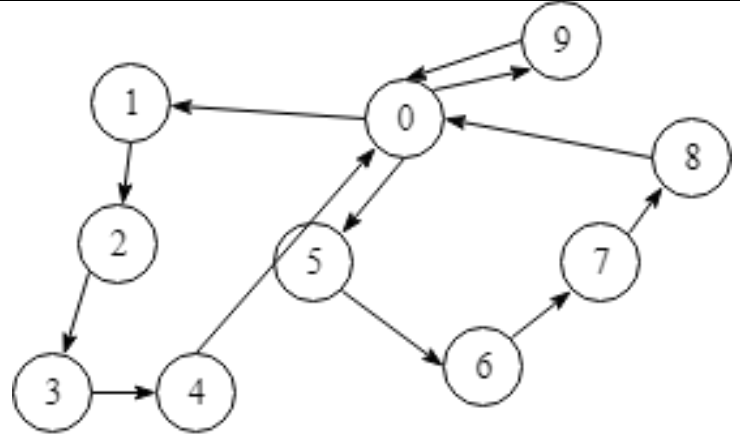

Figure 4. The distribution route of the sweeping algorithm

\subsection{Distribution scheme based on neighbor algorithm}

In this method, the nearest customer to the distribution center is regarded as the initial solution, and the point where the initial solution and the distribution center are located at a short distance is selected as the next delivery customer. According to the above, the customers who satisfy the 
condition are determined by the condition that the freight volume does not exceed the carrying capacity of the vehicle, the total transportation mileage is not more than 600 and the time range is the constraint condition. The nine customers of the logistics enterprise use the sweeping algorithm to optimize the distribution route. The neighbor algorithm optimization scheme is shown in Table 9. The calculation results of the neighbor algorithm are shown in Table 10. The diagram of the neighbor algorithm is shown in Figure 5.

Table 9. The neighbor algorithm optimization scheme

\begin{tabular}{|l|l|l|l|l|}
\hline Loop & Distance & $\begin{array}{l}\text { The volume of } \\
\text { goods }\end{array}$ & $\begin{array}{l}\text { Car model } \\
\text { drivers }\end{array}$ \\
\hline $0-1-2-5-8-0$ & $355.9 \mathrm{~km}$ & 94 & 10 tons of cars & 2 \\
\hline $0-6-7-9-0$ & $323.2 \mathrm{~km}$ & 98 & 10 tons of cars & 1 \\
\hline $0-3-4-0$ & $376.3 \mathrm{~km}$ & 36 & 6 tons of cars & 2 \\
\hline
\end{tabular}

Table 10. The calculation results of the neighbor algorithm

\begin{tabular}{|l|l|l|l|l|}
\hline Item & Total mileage & $\begin{array}{l}\text { Fuel } \\
\text { consumption }\end{array}$ & $\begin{array}{l}\text { Number of } \\
\text { drivers }\end{array}$ & Total cost \\
\hline $\begin{array}{l}\text { Neighbor } \\
\text { algorithm }\end{array}$ & 1132.8 & 251.8 & 5 & 2525.2 \\
\hline
\end{tabular}

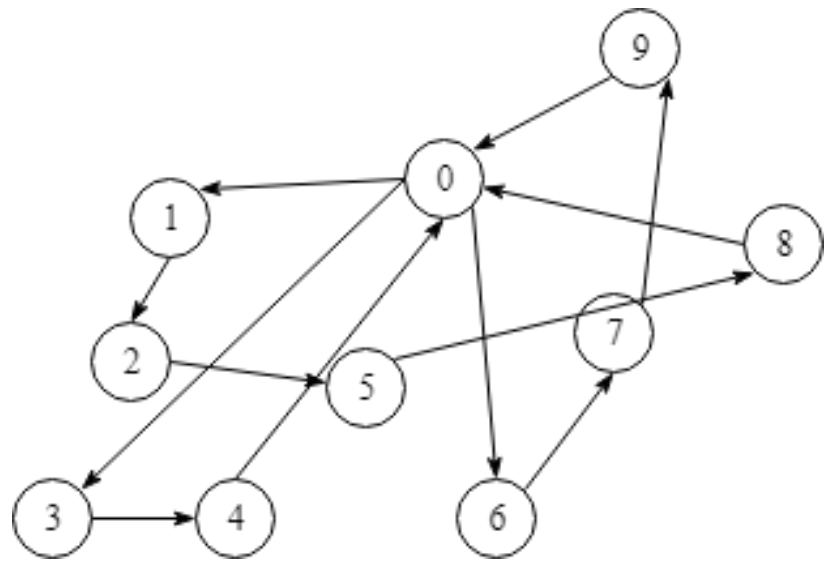

Figure 5. The diagram of the neighbor algorithm

\section{Results analysis}

The comparison of the schemes before and after optimization is shown in Table 11.

Table 11. The comparison of the schemes before and after optimization

\begin{tabular}{|l|l|l|l|l|}
\hline \multirow{2}{*}{ Item } & \multirow{2}{*}{$\begin{array}{l}\text { Before } \\
\text { optimization }\end{array}$} & $\begin{array}{l}\text { Saving } \\
\text { algorithm }\end{array}$ & $\begin{array}{l}\text { Sweeping } \\
\text { algorithm }\end{array}$ & $\begin{array}{l}\text { Neighbor } \\
\text { algorithm }\end{array}$ \\
\hline $\begin{array}{l}\text { Total distance of } \\
\text { transportation } \\
(\mathrm{km})\end{array}$ & 1283.8 & 946.7 & 947.7 & 1132.8 \\
\hline $\begin{array}{l}\text { Fuel } \\
\text { consumption (L) }\end{array}$ & 256.76 & 230.7 & 236.3 & 251.8 \\
\hline $\begin{array}{l}\text { Number of } \\
\text { drivers }\end{array}$ & 6 & 4 & 5 & 5 \\
\hline Cost (yuan) & 2710.6 & 2226.4 & 2415.9 & 2525.2 \\
\hline
\end{tabular}

As can be seen from Table 3, the original distribution scheme not only costs manpower, but also costs money, which is not recommended. However, the latter three methods have different degrees of savings. By comparing the latter three methods, it can be seen that the saving algorithm is superior. For the above practical problems, this article gives only three verification methods. In the 
future, more methods need to be explored. In addition, the actual problems vary widely, and it is even more necessary to devote more efforts to studying more and better ones.

\section{Conclusions}

On the basis of reading a large number of excellent papers, the optimal route of distribution and the minimum time of production are studied. The model of vehicle scheduling problem based on time window is introduced first. Then, the actual operation of a specific logistics and distribution company was chosen as an example. By using the saving algorithm, sweeping algorithm and neighbor algorithm, the specific delivery scheme with time window constraint is solved. Finally, the three schemes are compared with the original ones. The original distribution scheme not only consumes manpower, but also consumes financial resources. It's not practical. However, the three methods proposed in this paper can save costs in varying degrees. By comparing the three methods, the results show that the saving algorithm is superior. However, in terms of logistics development, the corresponding management system cannot fully meet the needs of development. The study of vehicle scheduling problem optimal route and the discussion of optimal time are not accurate enough, and there is still room for improvement.

\section{REFERENCES}

[1] Liberatore, F., Ortuño, M. T., Tirado, G., Vitoriano, B., \& Scaparra, M. P. (2014). A hierarchical compromise model for the joint optimization of recovery operations and distribution of emergency goods in Humanitarian Logistics. Computers \& Operations Research, 42, 3-13.

[2] Camacho-Vallejo, J. F., González-Rodríguez, E., Almaguer, F. J., \& González-Ramírez, R. G. (2015). A bi-level optimization model for aid distribution after the occurrence of a disaster. Journal of Cleaner Production, 105, 134-145.

[3] Demirel, E., Demirel, N., \& Gökçen, H. (2016). A mixed integer linear programming model to optimize reverse logistics activities of end-of-life vehicles in Turkey. Journal of Cleaner Production, 112, 2101-2113.

[4] Govindan, K., Soleimani, H., \& Kannan, D. (2015). Reverse logistics and closed-loop supply chain: A comprehensive review to explore the future. European Journal of Operational Research, 240(3), 603626.

[5] Yang, J., Guo, J., \& Ma, S. (2016). Low-carbon city logistics distribution network design with resource deployment. Journal of Cleaner Production, 119, 223-228.

[6] Wang, Y., Ma, X., Xu, M., Liu, Y., \& Wang, Y. (2015). Two-echelon logistics distribution region partitioning problem based on a hybrid particle swarm optimization-genetic algorithm. Expert Systems with Applications, 42(12), 5019-5031.

[7] Khayyam, H., Naebe, M., Bab-Hadiashar, A., Jamshidi, F., Li, Q., Atkiss, S., ... \& Fox, B. (2015). Stochastic optimization models for energy management in carbonization process of carbon fiber production. Applied Energy, 158, 643-655.

[8] Negenborn, R. R., \& Maestre, J. M. (2014). Distributed model predictive control: An overview and roadmap of future research opportunities. IEEE Control Systems, 34(4), 87-97. 